\title{
Informal employment in emerging and transition economies
}

\section{Reducing informality requires better enforcement, more reasonable regulation, and economic growth}

Keywords: informality, shadow economy, mobility, exclusion

\section{ELEVATOR PITCH}

In developing and transition economies as much as half the labor force works in the informal sector (or "shadow economy"). Informal firms congest infrastructure and other public services but do not contribute the taxes needed to finance them. Informal workers are unprotected against such negative shocks as ill-health, but for certain groups there can be scarce opportunities to enter the formal sector meaning informal employment is the only feasible option. Reducing informality requires better enforcement, more reasonable regulation, and economic growth.

\section{KEY FINDINGS}

\section{Pros}

๑ Informal entrepreneurship is a source of upward mobility.

๑ Informality is a rational response to excessive regulation and low institutional quality.

- In some cases, informality is an escape from extortion by corrupt officials and inspectors.

๑ Informal employment can be the opportunity of last resort for excluded workers.

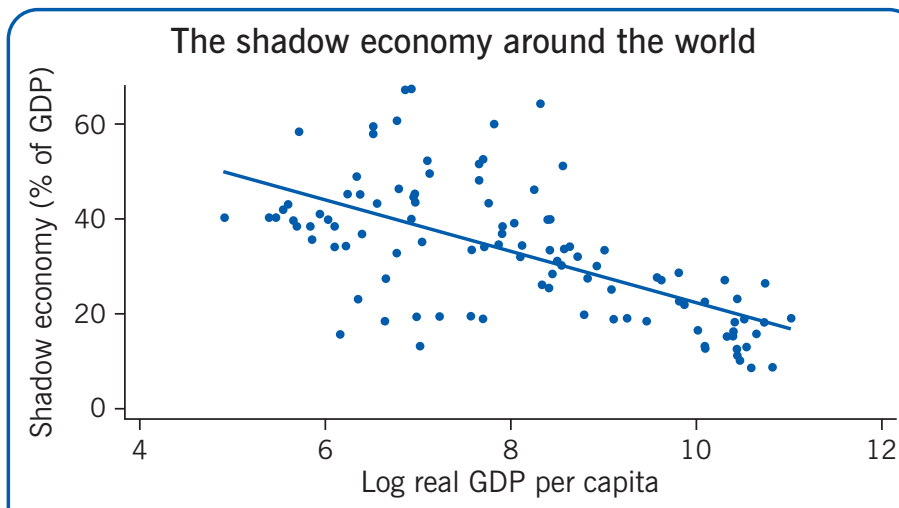

Source: [1]; and World Bank, World Development Indicators. Online at: https://databank.worldbank.org/source/world-development-indicators

\section{Cons}

- Workers might be locked in to informal jobs.

- Informal firms are sub-optimally small and lack access to credit and contract enforcement; furthermore they free-ride on public services and undercut formal competitors.

- Informal workers are largely unprotected from the risks of ill-health, old age, and maternity.

- Generalized informality can lead to severe problems for public finance.

- Reducing the costs of formalization has very limited effects on firms' decisions to register formally.

\section{AUTHOR'S MAIN MESSAGE}

Informality can be the result of restrictions that exclude some workers from formal positions. But many studies suggest that labor markets are well integrated, implying that a large fraction of informal employment is voluntary. Poverty alleviation efforts should thus be focused on vulnerable groups and bad times (recessions). And reforms that improve the balance of benefits and costs of formal employment can reduce informality. 


\section{MOTIVATION}

Informality characterizes a large set of economic activities in developing countries, including small enterprises, self-employed individuals, and informally hired employees working for otherwise formal firms. Its extent varies widely depending on the country and the measure, but estimates of about half of the labor force are common. Informal employment is associated with many negative outcomes: tax evasion, corruption, illegal activities, low investment rates, misallocated resources, uninsured workers, et cetera.

The initial approach of governments has been to persecute informal firms and entrepreneurs-and to provide assistance to informal workers who lack the protection of a formal safety net.

Informality is a response to inadequate or excessive regulation of markets and to the low quality of public insurance systems. Some individuals choose informality in much the same way they choose an occupation: it is the best available alternative, given their skills, information, and expectations. Informal entrepreneurship may provide opportunities for social mobility otherwise unattainable. Informal networks of family and friends can partly substitute for unreliable welfare systems. In cases of widespread government corruption, informality might be an escape from extortion by public officials and inspectors.

\section{Alternative definitions and measures of informality}

The informal sector is also referred to as the shadow, black, or hidden economy. The exact definition and measurement vary widely, depending on the data and the research goals.

"Productive" definitions: Informality is considered an attribute of a firm or unit of production. For example, a firm can be considered informal if it avoids taxes or regulations, or if it lacks a legal entity separate from its owners, a formal accounting system, and so on. In some cases, any activity not registered by the state is considered informal.

Social protection or "legalistic" definitions: Informality is seen as an attribute of a job. Informal employees are those not covered by labor market institutions like the minimum wage, union-bargained collective contracts, and social security.

\section{DISCUSSION OF PROS AND CONS}

\section{The dualistic view: Rural and urban}

The early literature on informality related it to rural-urban migration. In the HarrisTodaro model, only a fraction of workers in the urban labor force has access to jobs in the regulated formal sector. The reason behind the segmentation of formal jobs is a minimum wage set higher than the market clearing level. Other possibilities include union collective bargaining, public-sector wage policy, and efficiency wages.

This conceptualization of the informal sector has implications. First, informality is involuntary. Informal workers would prefer a formal job if one were available because formal jobs pay higher wages and offer all the mandatory benefits in the labor code. In contrast, informal activities are in principle uncovered by social protection laws. 
Second, many apparently pro-worker policies could have perverse effects. In particular, any attempt to encourage job creation in the formal urban sector could lead to more unemployment and more informality. The reason is simple. As long as the formal wage is above the remuneration to labor in rural areas, expanding formal employment will lead to more intense rural-urban migration. So, the only real antidote to informality and urban unemployment is rural development.

While the link between rural development and urban informality appears intuitive, there is almost no evidence backing it up. Recent studies have found that improving public infrastructure and facilities in rural villages had either no effect or even encouraged migration to cities.

\section{Firm-size dualism: The missing middle}

Since the beginning, observers of the informal sector have pointed out that informal operations are small. The typical "firm" is a self-employed individual working alone or with a handful of dependents (on many occasions, family and friends).

In the Rauch model of the informal economy, the minimum wage is binding only for firms larger than a certain threshold. This could be the case if, say, the government directed limited enforcement resources to large firms to maximize coverage. The point would also hold if the formal wage is set by union collective bargaining contracts, since it is easier for unions to organize in larger establishments. In this setup there is a break in the size distribution of firms (rather than a continuum) between those paying the minimum wage and those not. Size dualism has deservedly received a lot of attention. Small firms face obstacles that make them less productive and retard their growth. It is harder for them to secure external finance and attain an efficient scale of production. Moreover, government industrial policies often focus on medium to large enterprises, implicitly putting smaller firms at a disadvantage.

Perhaps because the theoretical case for a "missing middle" is so persuasive, its existence has been taken for granted in much of the literature on informality. In recent years, comprehensive data sets covering both formal and informal firms have become available and, as a result, the idea of a "missing middle" in the size distribution of firms has been disputed. For several emerging economies, including India, Indonesia, Mexico and Brazil, there seems to be little to no evidence of a bimodal firm size distribution $[2],[3]$.

\section{The formal wage premium}

One key implication of dualistic models is a difference between the formal sector wage and the informal sector wage for economically identical workers. While there is no controversy that average pay in formal jobs is higher, it is also known that many informal workers-especially the self-employed and micro-entrepreneurs-have relatively high earnings. In addition, several recent studies suggest that once the differing characteristics of the workers and jobs are taken into consideration, the average formal wage premium almost vanishes. 
An interesting example uses Argentina's biannual household survey [4]. Depending on the exact definition and period, simple comparisons of wages in the formal and informal sector give a formal premium of $30-40 \%$. These figures can be deeply misleading, however, because workers in the informal sector have characteristics that make them less productive. For example, the proportion of employees with a university degree is about $20 \%$ for formal jobs but only about $11 \%$ for informal jobs. To obtain a wage premium that controls for these and other factors, the study uses a matching technique. In essence, it compares the wages of formal workers with the wages of the informal workers whose characteristics are very similar and then averages these differences over the whole sample. Depending on the specification, the adjusted formal premium ranges between $-18 \%$ and $11 \%$, and is never statistically different from zero. The key characteristic driving the naïve formal wage premium is firm size: what appears to be a formality premium is in reality a firm-size premium. Similar results have been found in studies of Ecuador, South Africa, and Côte d'Ivoire.

These findings are further confirmed by a recent study that exploits the availability of matched employer-employee data on both formal and informal firms in Brazil to estimate the formal-informal wage gap while introducing firm fixed effects [5]. Controlling for the time-invariant characteristics of firms results in the wage gap between formal and informal workers completely vanishing.

\section{Informality and mobility}

If formal employment is preferable to informal work, workers should queue up for formal sector jobs. So turnover in the formal sector should be very limited. And flows between the formal and informal sectors should be roughly unidirectional, with formal workers taking informal jobs only in extraordinary circumstances.

A study that analyzes worker transitions across sectors using panel data from Mexico finds high mobility, with turnover rates in the formal sector similar to those in the relatively unregulated US labor market [6]. Contrary to the predictions of the dualistic view, flows between sectors are roughly symmetric.

These mobility patterns suggest that the labor market in countries like Mexico can be better understood with a competitive model, in which individuals with diverse preferences and abilities choose between sectors according to the offered wages but also the bundle of benefits and associated costs. The informal sector has some positive features, including flexibility and autonomy, especially for self-employed individuals. Informal employees, given their education and experience, might not have better opportunities in the formal sector. And poor institutional design can make participation in public insurance programs unappealing, especially if coverage can be obtained through alternative means (as through a spouse with a formal job).

Recent research has provided more formal tests of the hypothesis that the Mexican labor market is competitive and integrated. A dynamic model of sector choice has been used to test the hypothesis that job separation rates are equal in both sectors and that, on average, obtaining a formal sector job is as hard as obtaining an informal sector job. Separate tests for men and women of different skill levels lead to the same conclusion. 
For transition economies, the evidence is more mixed-probably because self-employment in these countries is fairly rare, and most informal workers are dependent employees (see Figure 1). A study analyzing panel data from Ukraine finds evidence of segmentation and a two-tier wage structure in the informal sector [7]. A study estimating a so-called dynamic multinomial logit model of sector choice that allows for individual variation in preferences using Russian panel data finds little evidence of segmentation [8]. Another study uses a novel data set that permits reconstructing the complete employment history of a representative sample of Russian adults for 2003-2008 to analyze the effect of job separations on informality. It finds that displacement entraps some workers in involuntary informal employment.

More recently, thanks in large part to the availability of firm-level data sets covering both the formal and the informal sector, a quite different perspective has arisen. In

Figure 1. Composition of informal employment in five emerging and transition economies

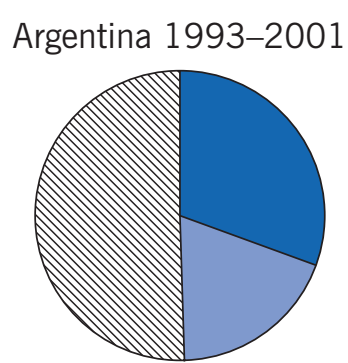

Mexico 1987-2004

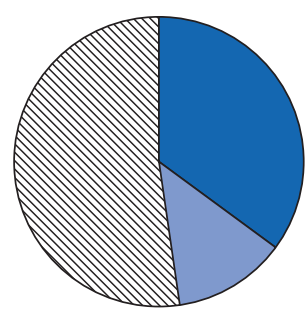

Informal self-employed $\square$ Informal salary

$\mathbb{Q}$ Formal salary

国 Formal entrepreneur

Irregular activity

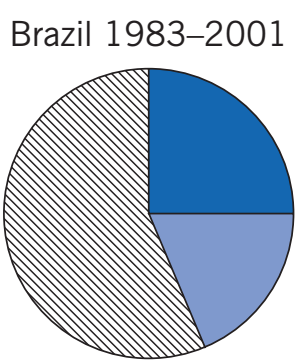

Russia 2002-2011

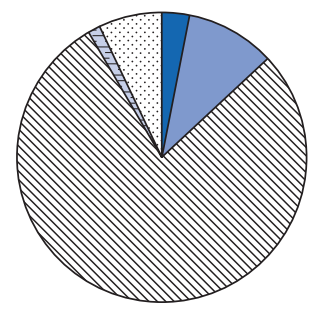

Ukraine 2003-2004

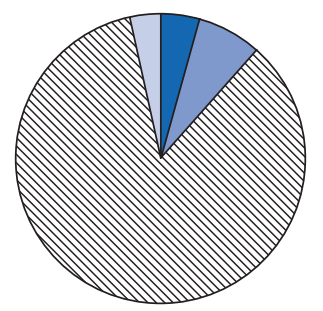

Source: Data for Argentina, Brazil, and Mexico are from Bosch, M., and W. F. Maloney. "Comparative analysis of labor market dynamics using Markov processes: An application to informality." Labour Economics 17:4 (2010): 621-631

[10]; data for Russia are from Slonimczyk, F., and V. Gimpelson. Informality and Mobility: Evidence from Russian Panel Data. IZA Discussion Paper No. 7703, 2013 [8]; data for Ukraine are from Maloney, W. F. "Does informality imply segmentation in urban labor markets? Evidence from sectoral transitions in Mexico." The World Bank Economic Review 13:2 (1999): 275-302 [6]. 


\section{Informality in transition economies}

Informality in transition economies is somewhat unique. A successful transition to a market economy implies that the biases characteristic of planned economies have disappeared: labor has to be reallocated from state enterprises to the private sector, from large firms to small and medium-size firms, and from industry into services. Informality tends to be more prevalent in firms with exactly the desired characteristics: they are de-linked from the state economy, small, and predominantly in the service sector. So developing a large informal economy is an intrinsic risk of transition. Because tax revenues decline with a rising share of informal activity, transition economies can end up either in a good equilibrium with a small informal sector and high tax revenues or in a bad equilibrium with a large informal economy and low tax revenues.

Source: Johnson, S., D. Kaufmann, A. Shleifer, M. I. Goldman, and M. L. Weitzman. "The unofficial economy in transition." Brookings Papers on Economic Activity 28:2 (1997): 159-239.

contrast to what is known about workers, informal firms rarely transition to formality and continue their existence, often for years or even decades, without much growth or improvement [9].

There are two main explanations for the slow firm-level transition to formality. The first is the limited extent of the market (insufficient size to reach the minimum efficient scale of production). The second involves limitations in the entrepreneurial and management skills of informal entrepreneurs. The available evidence suggests that managers of informal firms would not be able to just start larger formal firms and operate them well enough to survive in the formal sector: they would not know how to.

In sum, mobility across sectors has been studied for many countries and periods. In general, studies find higher integration in the labor market than would be reasonable to expect in a strongly dualistic world. Another frequent finding is that for certain groups (unskilled workers, youth, and displaced workers), opportunities to enter the formal sector can be scarce. Finally, firm-level data seem to suggest that the dualistic view is not without merit.

\section{Informality in good times and bad}

Standard matching models predict that the shocks that drive the business cycle increase vacancies and therefore also the flow toward employment. In a competitive model with formal and informal jobs, both sectors react positively to the productivity shock. There is a positive correlation across bilateral flows, since employment in both sectors is procyclical. In contrast, a dualistic view would predict a negative correlation, as the probability of an involuntary transition from the formal to the informal sector is lower in good times than in bad-whereas transitions from informality to the formal sector follow the opposite pattern.

Analyzing data for Mexico and Brazil, a study finds positive correlations for transition intensities between formal and informal employment, and even stronger results for transitions between formal employment and self-employment [10]. But when results are broken down by age group, the correlation between formal and informal employment is negative for young workers (ages 16-24). The conclusion is that voluntary entry accounts 
for a substantial part of the informal sector, particularly among those who are selfemployed, although informal salaried work, particularly among young workers, appears to correspond more closely to the "standard queuing view."

Another study that focuses on the informal sector over the business cycle uses Argentinean data to show that the self-employed sector is segmented. Own-account workers form a large majority of the sector. They have a lower propensity to exit to salaried work or become employers. Transition into this category is common during recessions, a trend that is reversed in expansionary periods. This finding supports the view that being an own-account worker is a form of disguised unemployment. Well-remunerated salaried workers are more likely to become entrepreneurs with employees, probably because it is easier for them to gather the start-up capital. So the likelihood of transitioning into this category is positively related to the individual's accumulated labor market experience and education level.

\section{The competitive view: Diverse workers and jobs}

An important strand in the literature has developed the idea that labor markets are competitive, not segmented: the informal sector arises because individuals have different abilities and preferences. A simple model posits two possible sources of income: individuals can offer their labor services for an externally determined wage, or they can engage in (informal) self-employment. The key assumption is that managerial ability is an important input for self-employed activities. Individuals with high managerial ability find it optimal to choose self-employment, and individuals with low managerial ability specialize in wage employment.

The idea that informal self-employed individuals have special talents has been extended to explain some stylized facts. One competitive model allows managers to self-finance part of their capital with savings and also borrow funds from an intermediary. Access to outside financing is better in the formal sector. But unlike informal managers, formal managers are subject to taxes. In this setting, the most talented managers self-select into the formal sector and operate with more physical capital than informal managers. In turn, assuming that capital and skill are complements in production, skilled labor will be more prevalent in the formal sector.

Related work explores the idea that entrepreneurial ability is revealed only through experience. Informality might be a stepping stone to formal entrepreneurship by providing a testing ground for individuals to learn-at fairly low cost-how profitable their projects are.

\section{The competitive view: Taxation and public services}

An influential study investigates the interactions among taxation, enforcement, institutional quality, the size of the informal sector, and the rate of economic growth [11]. In the Loayza model, government services increase the rate of return to capital in both the formal and the informal sectors, but only formal firms pay taxes to finance them. The relative size of the informal sector depends positively on the rate of taxation and the ability of informal firms to free-ride in government services-and negatively on the strength of enforcement and the quality of public institutions. 
Many researchers have pursued the idea that the informal sector is primarily a tax- and regulation-avoiding sector (the "shadow economy"). One study estimates the size of the sector (as a percentage of GDP) for 110 countries in all regions of the world [1]. While informal activity is relatively more prevalent in developing countries, the size of the shadow economy is far from negligible even in industrialized countries (see the Illustration on p. 1). Using these data, the study finds that an increasing burden of taxation and social security payments is the major driving force underlying the size and growth of the shadow economy.

A recent study uses a survey of firms in Brazil to show that the credit method used to collect value-added tax creates informality chains, that is, clients or suppliers of informal firms are more likely to be informal [12]. When value-added tax is applied in a single stage of production at a rate estimated by the authorities, these chain effects disappear.

Another study exploits a natural experiment created by the Russian flat tax reform of 2001 to estimate the effect of taxation on informal employment [13]. The reform dramatically reduced marginal tax rates of the personal income tax for high-earning individuals but left the lower income bracket unaffected. It also led to a significant reduction in the fraction of informal employment, especially in informal irregular activities.

Several developing countries have attempted to simplify the tax code and reduce the tax burden in hopes of formalization. In the mid-1990s Brazil enacted the SIMPLES system, which greatly simplified and reduced the tax burden for micro and small enterprises. Recent evaluations of the effect of the program using data from Brazilian small firms have found that the program increased licensing rates and the number of firms registered as formal legal entities.

\section{Micro-enterprises and the social contract}

Since informality is fundamentally a micro-enterprise phenomenon, it is important to understand the cost-benefit analysis of small entrepreneurs. The state must offer a "deal" (social contract) that entrepreneurs and workers can accept. There are several elements to this contract, including both taxation and other costs of formality, but also the benefits that accrue to formal workers (especially the reliability of the pension system) and firms (improved access to credit and property rights protection).

But cost-benefit analysis cannot explain all behavior. Individuals might choose to go informal out of concerns that the tax system is unfair. Social norms also matter. Confessing to avoiding taxes to close friends and relatives is probably a big deal in Switzerland, but not in South America. In many developing countries there is a "culture of informality," and policies attempting to reduce informality must contend with this fact.

\section{Formalization experiments}

In part due to the increasing influence of the integrated markets view, several countries have experimented with policies that attempt to reduce the costs associated with formalization (especially registration costs). Several recent studies have analyzed the outcomes of these policies with mixed results. Reducing the costs of entering the formal sector seems to have very limited effects on firms' decisions to become formal [9]. 


\section{A segmented informal sector?}

There is a position that synthesizes aspects of the dualistic and the competitive labor market [14]. This middle way sees the informal sector as having its own internal duality: some informal activities are preferable to formal sector jobs, and some are not. Here the first segment is referred to as "upper-tier" informal activities and the second as "easy-entry." While the upper-tier activities are voluntary, the easy-entry jobs are better understood as a survival strategy for those excluded from the formal sector.

This position has the potential to rationalize the different findings about the informal sector: wide dispersion of earnings and well-being among informal workers, high mobility across sectors in some cases but not others, and so on. But it provides no method to determine which informal jobs correspond to which tier. Even an aggregate estimate of the fraction of the informal sector that is involuntary might be hard to obtain.

\section{Two margins of informality}

A different approach to reconciling the dualistic and non-dualistic views builds on the distinction between two different margins of informality: (i) whether firms register and pay entry fees to achieve a formal status, the extensive margin; and (ii) whether firms that are formal in the first sense hire workers "off the books," the intensive margin [5]. Fitting a structural model in which both margins of informality are relevant to data on formal and informal firms in Brazil allows a decomposition of the informal sector into three distinct parts. The first part involves firms that are potentially productive and that formalize and succeed when the formal sector's entry costs are removed. It constitutes a small fraction of all informal firms (11.5\%). The second part contains informal firms that choose informality to exploit the cost advantages of noncompliance even though they are productive enough to survive in the formal sector. It corresponds to a large fraction (35.9\%) of all informal firms. Finally, the remaining firms correspond to those too unproductive to ever become formal.

\section{LIMITATIONS AND GAPS}

"Informality" is an umbrella term that covers many concepts. It is not a foregone conclusion that the findings in the reviewed studies would remain the same under every definition of the informal sector.

While the literature on the informal sector is extensive and covers studies that use data from different countries and regions, many of the conclusions cited here might be relevant in some cases but not others. In other words, some results might not be externally valid and thus might not be applicable to countries and periods other than the ones analyzed.

\section{SUMMARY AND POLICY ADVICE}

After decades of research on the informal economy there is an emerging consensus that the old models overemphasize duality and segmentation. Most labor markets are relatively well integrated. Informal workers can-and often do-find a formal job. 
Other evidence supports the competitive view. Rural development projects have either no effect on rural-urban migration flows or-in some cases-even increase them. This result contradicts basic predictions from dualistic models. Wage differentials across sectors are small after adjustments to control for the differing characteristics of formal and informal workers. And self-employed individuals and other entrepreneurs choose the sector they operate in based on a cost-benefit analysis. In particular, simplifying the tax code and reducing tax rates tend to reduce informality. But for certain vulnerable groups, many workers end up informally employed during downturns.

Real-world labor markets are probably a mix of the stylized pictures from the different models. Some workers choose the informal sector because it offers them better opportunities of upward mobility. Others end up there against their best efforts.

The policy response should correspondingly be mixed. The dualistic models, which suggest that informality is involuntary, were often a rationale for poverty alleviation efforts. The empirical literature does not support arguments against such policies, but suggests that efforts focus on particular groups (young unskilled workers) and time periods (recessions).

The competitive view emphasizes balancing the benefits and costs of operating formally. Simplifying tax codes and reducing tax rates can induce formalization. Improving public insurance programs-especially pension systems-can also reduce informality. But where trust in public institutions is low, contributions to the system are seen as plain taxes, discouraging participation.

Governments should also emphasize policies that increase productivity and earnings in the formal sector. Improving the reach and quality of the education system contributes to economic growth and provides incentives to work formally.

Some of the causes of informality do not fit entirely within either view. To the extent that informality is due to social norms that discourage collaboration with state institutions, neither poverty alleviation nor individual incentives will exert much influence. The fight against the "culture of informality" requires measures to persuade the public that government intervention favors the public good, not some minority interests.

\section{Acknowledgments}

The author thanks an anonymous referee and the IZA World of Labor editors for many helpful suggestions on earlier drafts. All errors are the author's own. Version 2 of the article introduces a new con, finds new evidence that shows informal firms rarely formalize, and adds new "Key references" [2], [3], [5], [9], [12].

\section{Competing interests}

The IZA World of Labor project is committed to the IZA Code of Conduct. The author declares to have observed the principles outlined in the code.

(C) Fabián Slonimczyk 


\section{REFERENCES}

\section{Further reading}

De Soto, H. The Other Path: The Economic Answer to Terrorism. New York: Basic Books, 1989.

Perry, G., W. Maloney, O. Arias, P. Fajnzylber, A. Mason, and J. Saavedra. Informality: Exit and Exclusion. Washington, DC: World Bank, 2007.

Portes, A., M. Castells, and L. Benton. The Informal Economy. Studies in Advanced and Less Developed Countries. Baltimore, MD: The John Hopkins University Press, 1989.

\section{Key references}

[1] Schneider, F. "Shadow economies around the world: What do we really know?" European Journal of Political Economy 21:3 (2005): 598-642.

[2] Ulyssea, G. "Informality: Causes and consequences for development." Annual Review of Economics 12 (2020): 525-546.

[3] Hsieh, C. T., and B. A. Olken. "The missing 'missing middle'." Journal of Economic Perspectives 28:3 (2014): 89-108.

[4] Pratap, S., and E. Quintin. "Are labor markets segmented in developing countries? A semiparametric approach.” European Economic Review 50:7 (2006): 1817-1841.

[6] Maloney, W. F. "Does informality imply segmentation in urban labor markets? Evidence from sectoral transitions in Mexico." The World Bank Economic Review 13:2 (1999): 275-302.

[5] Ulyssea, G. "Firms, informality, and development: Theory and evidence from Brazil." American Economic Review 108:8 (2018): 2015-2047.

[7] Lehmann, H., and N. Pignatti. Informal Employment Relationships and Labor Market Segmentation in Transition Economies: Evidence from Ukraine. IZA Discussion Paper No. 3269, 2007.

[8] Slonimczyk, F., and V. Gimpelson. Informality and Mobility: Evidence from Russian Panel Data. IZA Discussion Paper No. 7703, 2013.

[9] La Porta, R., and A. Shleifer. "Informality and development." Journal of Economic Perspectives 28:3 (2014): 109-126.

[10] Bosch, M., and W. F. Maloney. "Comparative analysis of labor market dynamics using Markov processes: An application to informality." Labour Economics 17:4 (2010): 621-631.

[11] Loayza, N. V. "The economics of the informal sector: A simple model and some empirical evidence from Latin America." Carnegie-Rochester Conference Series on Public Policy 45:1 (1996): 129-162.

[12] De Paula A., and J. A. Scheinkman. "Value-added taxes, chain effects, and informality." American Economic Journal Macroeconomics 2 (2010): 195-221.

[13] Slonimczyk, F. "The effect of taxation on informal employment: Evidence from the Russian flat tax reform." Research in Labor Economics 34 (2012): 55-99.

[14] Fields, G. S. A Guide to Multi-Sector Labor Market Models. School of Industrial Labor Relations Working Paper, 2004.

\section{Online extras}

The full reference list for this article is available from:

https://wol.iza.org/articles/informal-employment-in-emerging-and-transition-economies

View the evidence map for this article:

https://wol.iza.org/articles/informal-employment-in-emerging-and-transition-economies/map 